\title{
Research on the Construction of Financial Sharing Service Platform Based on ERP Supply Chain Management in the Cloud Computing Environment
}

\author{
LongMeiWang ${ }^{1,}$ a , JingSong ${ }^{2, ~ b, ~ * ~}$ \\ ${ }^{1}$ Macau Univ Sci \& Technol, Sch Business, Ave Wai Long, Taipa, Macau, Peoples R China \\ ${ }^{2}$ Macau Univ Sci \& Technol, Sch Business, Ave Wai Long, Taipa, Macau, Peoples R China \\ a34502101@qq.com, b877822256@qq.com \\ *JingSong
}

\begin{abstract}
Keywords: Cloud computing environment; ERP supply chain management; Financial sharing service platform; Financial management mode
\end{abstract}

\begin{abstract}
Big data, cloud computing and Internet of Things are increasingly influencing the management changes of enterprises. The future financial management mode of enterprises is bound to be integrated with the cloud service model. The financial sharing service center will also adopt the cloud service approach to provide professional financial management services. Based on ERP supply chain management in cloud computing environment, this paper analyzed the construction of financial sharing service platform and explored the main value of the implementation of China's financial sharing platform with the case of specific enterprise groups. Although more and more mature cloud computing services are recognized by more and more people, there is great room for cloud computing services to grow and it is worth the relevant personnel to continue their exploration and research.
\end{abstract}

\section{INTRODUCTION}

The 21 st century is witnessing waves of globalization. During the process, social and economic development have encountered unprecedented challenges, which means that industrial organizations are facing the need of reshaping. Likewise, commercial models are forced to constantly change, and innovation in management philosophy is in the ascendant. With the continuous development of economic globalization, the scale of enterprises has been constantly expanding, more and more multinational enterprises have emerged, and the integration and reorganization among enterprises have become more frequent [1]. This enhances the core competitiveness of enterprises, risk resistance and long-term development capability. Faced with a complex business environment and ever-changing market, how to obtain better technology and profit at the lowest cost while maintaining an efficient management mechanism and operation flow has become an important challenge for the development of the enterprise [2]. In this one, financial management handles the core position and plays an important role. Under the background of economic globalization, we need to know how to strengthen the management and control over the subsidiaries of the parent company, how to effectively reduce the financial management and operating costs of the entire enterprise, how to maximize the value of the entire enterprise, how to change the asset structure. We should improve operational efficiency and other issues which are the enterprises in the development process facing an important issue. As for the vast majority of SMEs, how to gain their own place in the increasingly fierce market competition and gradually expand the scale of the enterprises are the important problems they face [3].

\section{STATE OF THE ART}

In big data environment, the characteristics of data and the demands of data processing all set new requirements for the financial sharing service [4]. First of all, for the mass data, the financial 
sharing service center cannot use all the data as the data source, and we must select the database that meets the requirements from the massive data from the perspective of the enterprise's financial strategy. The second is more diversified financial data, including unstructured financial data which greatly increases the proportion of the need for financial sharing services for unstructured and convenient data processing methods and technologies. It is mainly from the unstructured data and financial statements relevance, etc., such as the confirmation of unstructured data and how to reflect the unstructured financial data through financial statements [5]. Lastly, under the background of big data, we must make full use of advanced information technologies such as cloud computing and artificial intelligence to improve the construction of financial shared service centers and strictly manage risks such as information technology, suppliers and data security. When the background of big data has not yet been formed, the financial sharing service is more and more applied in the enterprise. However, with the background of big data, the volume of financial data suddenly surges and forms a diversified pattern. The concept has not only limit to the internal part of the enterprise, but also cover the whole supply chain from the perspective of the whole industrial chain, making the boundary between enterprises more obscure [6]. At the same time, the financial sharing service, driven by big data, makes the continuous innovation of the financial sharing service. In particular, emerging technologies such as cloud computing and artificial intelligence have promoted the evolution of the financial sharing service [7].

\section{METHODOLOGY}

\subsection{Cloud computing impact on ERP}

Cloud computing is not a new technology, which has gone through the power plant model stage, utility computing stage, grid computing stage and eventually becoming more mature. Cloud computing is not so much a calculation as it is a service model. Cloud computing is with large-scale, super processing power and high scalability. In addition, cloud computing is the perfect system to combine powerful computing power built on inexpensive nodes. The emergence of "cloud" has brought tremendous impact on the ERP system. The impact of cloud computing on ERP mainly includes the following points, as shown in Table 1.

Table.1 Cloud Computing Impact on ERP

\begin{tabular}{|c|c|c|}
\hline influences & Specific performance \\
\hline $\begin{array}{c}\text { Increasing } \\
\text { convenience }\end{array}$ & $\begin{array}{c}\text { ERP users based on the cloud computing platform can not only use the system in } \\
\text { the enterprise intranet, but also use the system through the external wide area } \\
\text { network. The system can be used anywhere, anytime as long as there is a network. }\end{array}$ \\
\hline $\begin{array}{c}\text { Reducing the } \\
\text { cost of using } \\
\text { the system }\end{array}$ & $\begin{array}{c}\text { ERP users based on cloud computing platform do not need to buy a server and pay } \\
\text { for subsequent hardware maintenance costs. This directly reduces the cost of using } \\
\text { the system by the user, which not only improves system usage but also increases } \\
\text { system users. }\end{array}$ \\
\hline $\begin{array}{c}\text { Shorting the } \\
\text { ERP } \\
\text { construction } \\
\text { cycle }\end{array}$ & $\begin{array}{c}\text { Traditional ERP software goes through a long period of demand and } \\
\text { implementation of the process. The hardware investment and labor cost needed in } \\
\text { this process are very high. However, after using the ERP system based on the } \\
\text { cloud computing platform, the enterprises will not need to configure a large } \\
\text { number of professional and technical personnel to carry out the tracking exchange, } \\
\text { thus eliminating much tedious work and improving the work effectiveness. }\end{array}$ \\
\hline
\end{tabular}

\subsection{Based on cloud computing ERP mode}

(1) Cloud computing service model. Cloud computing is based on three service modes of SaaS (infrastructure, namely service), PaaS (platform as a service) and IaaS (software as a service), which deliver traditional IT products to users through the Internet, as shown in Table 2 
Table.2 Cloud computing service model

\begin{tabular}{|c|l|l|}
\hline $\begin{array}{c}\text { Service } \\
\text { mode }\end{array}$ & \multicolumn{1}{|c|}{ definition } & \multicolumn{1}{|c|}{ Specific functions } \\
\hline $\begin{array}{c}\text { SaaS } \\
\text { Model }\end{array}$ & $\begin{array}{l}\text { It is an operational } \\
\text { service model that is } \\
\text { highly dependent on } \\
\text { the Internet and mainly } \\
\text { for consumers. }\end{array}$ & $\begin{array}{l}\text { SaaS providers build their customers' software products on their } \\
\text { services over the Internet and then pay the SaaS provider for } \\
\text { rental services. Customers do not need to have a hardware } \\
\text { foundation, and professional foundation will be able to enjoy the } \\
\text { service. }\end{array}$ \\
\hline $\begin{array}{c}\text { PaaS } \\
\text { Model }\end{array}$ & $\begin{array}{l}\text { PaaS is platform as a } \\
\text { service. }\end{array}$ & $\begin{array}{l}\text { Users do not need server hardware and PaaS platform can be } \\
\text { directly used to develop their own needs applications. At the } \\
\text { same time, the application developed by using PaaS platform can } \\
\text { better build enterprise application platform oriented to service } \\
\text { architecture. }\end{array}$ \\
\hline $\begin{array}{c}\text { IaaS } \\
\text { Model }\end{array}$ & $\begin{array}{l}\text { IaaS provides users } \\
\text { with } \\
\text { infrastructure over the } \\
\text { network }\end{array}$ & $\begin{array}{l}\text { It is the lowest and most basic service that provides users with } \\
\text { standardized services such as basic storage resources, servers and } \\
\text { computing power on demand. }\end{array}$ \\
\hline
\end{tabular}

The ERP system and the cloud computing model are well-suited for the following reasons: (a) Organizational structure across enterprises is very common due to business needs, and cloud computing services can easily share remote information in real time. Enterprises simply have access to their resources and their services through the Internet, which greatly reduces the spatial distance between departments and departments. (B) ERP systems need real-time tracking, so they must have high-speed processing capabilities. With the expansion of business scale and the increase of accumulated data, the storage and analysis of data are also very important, and cloud computing service can well solve this problem. (C) ERP system implementation of modular sales. According to their needs, customers can assemble and assemble ERP system suitable for their own enterprise, and cloud computing service can meet diversified hardware requirements. (D) Rapid changes in enterprise size and demand. As cloud computing service is a leasing model that better solves this problem, it can meet customers' ever-changing hardware and architecture needs anytime and anywhere, and reduces user hardware investment and professional and technical personnel Maintenance costs.

(2) SOA architecture. SOA is a service-oriented architecture. It can be better modular. It will be a function of the software as a module, and the internal structure of the module or change does not affect the interface at all and you can maximize the reusability of the module.

(3) The combination of cloud computing service model and ERP. In the cloud-based ERP model architecture, SaaS provides various functional modules; and the service manager realizes the service management and security management of the cloud platform. Users can interact directly with tiers through the PC portal and handheld portal.

(4) Cloud-based ERP system security. Security based on cloud computing ERP system is the key point. Cloud computing is very flexible and convenient, but data privacy and security issues in cloud computing have always been the concern of all. First of all, the data in the cloud computing relies on the network transmission, and the requirements of the network security technology are very high. Secondly, the requirements of multi-tenant shared services and data management are also very high and data leakage problems cannot occur. Finally, for cloud computing providers, users' information and data, the data is transparent and cloud computing providers must take effective measures to ensure cloud computing ERP system security. ERP systems based on cloud computing have higher security requirements. Corporate data is very confidential, and it even concerns the survival of an enterprise. Therefore, based on the cloud computing, ERP system not only prevents virus attacks, but also avoids the interference of various data and reduces data leakage problems. With strict control of authority, using data encryption and data coloring methods achieves a comprehensive prevention. 


\section{RESULT ANALYSIS AND DISCUSSION}

\subsection{Group A financial sharing center development background}

With the continuous expansion of the Group's market and business as well as the development of economic globalization, Group A's internationalization strategy has become clearer and clearer. The decentralized financial management model has become less and less effective and has become less efficient:

(1) The contradiction between high cost and inefficiency. International market expansion makes Group A more and more institutions and related departments in the world. All branches, R \& D institutions and general sales departments need to establish a complete financial management system. Its labor cost and hardware facilities and other aspects are a huge expenditure; at the same time as the institutional sector too much, the mechanism reported to the summary level led to reduced efficiency, which lacks of timely information. The group's decision-making also has a significant impact.

(2) The quality of financial information is difficult to guarantee. An independent financial management system has great advantages for financial accounting and management of a single entity. However, for such a large-scale group A as the Group, the excessive decentralization of management methods such as molecular companies and R \& D institutions inevitably evolves to restrict its Very important factor in development. The main reason is that the financial management system and the corresponding financial management system of various molecular companies and $\mathrm{R}$ \& D institutions are different, increasing the difficulty of management and making it extremely deficient in the authenticity, accuracy and completeness of information.

(3) The guiding role of financial information in decision-making cannot be effectively guaranteed. In addition to the increased cost and the quality of financial information, decentralized financial management has another drawback in that financial information has had some impact on the development decisions of departments and enterprises. Due to the basic work of accounting and financial data to check the workload is large, which will take up a large number of financial staff time. The financial data consolidation and analysis of the time will naturally reduce the hidden data which cannot be hidden information which is bound to affect the business decision.

In order to better cope with the full implementation of Group A's internationalization strategy, we enhance the efficiency of its financial department, reduce its financial costs and give full play to its role in group decision-making, Group A pioneer the establishment of a financial sharing service center for the basic financial processes of handling all the subsidiaries. Research institutes and other departments affiliated to the group have greatly improved the work efficiency and free the finance staff from basic work.

\subsection{A Group financial cloud main content}

Group A's "Financial Cloud" is the global financial sharing service platform of Group A's communications group. Group A's financial cloud system is a financial sharing platform system based on cloud computing technology that fully utilizes the capabilities of cloud computing for interoperability, data storage and computing to deploy. Under the cloud platform, the traditional centralized accounting turn into a cloud processing, viewing and storage model of the original individual and accounting vouchers. Financial staff and managers can also view financial information from mobile terminals at any time to achieve the financial and business integration, but also support the realization of corporate strategy. Cloud computing technology to Group A financial process is more standardized. The financial center cloud data analysis and mining data relevance make the decision more reasonable. A group of "financial cloud" is able to succeed and the most important point is to establish a unified information system platform. The five systems of the platform are interlinked. From information collection to sharing and analysis, guaranteeing the accuracy, authenticity and timeliness of information, ensuring unification of accounting processes and reducing the working intensity of financial personnel, it more focuses on data management and distribution.

(1) Image management system. The image management system mainly includes four main 
modules of image acquisition, image transmission, business processing and information transfer, and it is responsible for different tasks, as shown in the following figure 1.

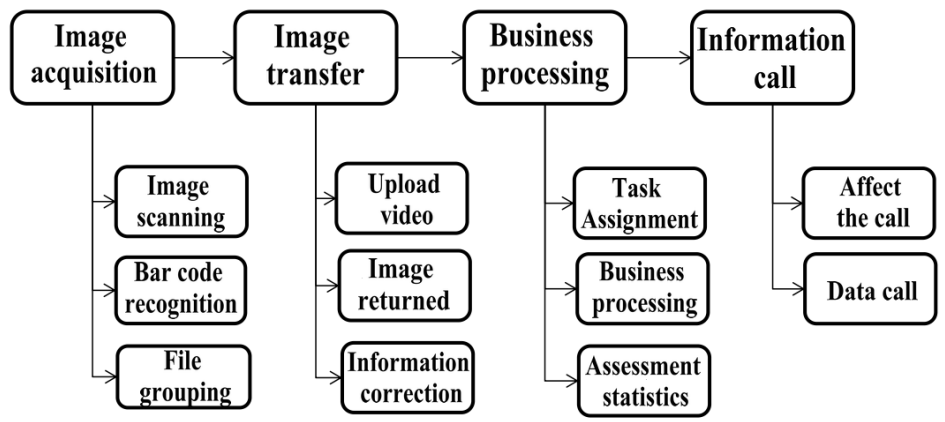

Fig.1 Image management system processing flow chart

Through the image acquisition of the original notes, the information in the images is identified and classified into groups. The financial officers upload the information to the business processing stage and can retrieve the images and data at any time if needed. Through such an efficient operation process, the physical flow in the financial process, the original vouchers and the offshore processing can be semi-automated, the business processing time can be shortened, and the original bills can be sent by mail on schedule, and the risk of document loss can also be reduced.

(2) Network reimbursement system. The application of the network reimbursement system is an important way to improve the efficiency of office work. From the production and approval of the previous documents to the mid-term accounting and report processing, and then to the application and maintenance of personal work platforms and other basic data, all achieved the paperless flow of information, timely and efficient accounting information to be processed, and it supports the final stage of decision-making. The network reimbursement system sets up different reimbursement templates according to different work needs. After the employees fill in the declaration information on the Internet, the basic information such as name, wooden door and account are automatically generated by the system. After the submission, the business leaders can be audited through the platform. Once the audits through, the information will be automatically transferred to the financial department. Through the review of the information submitted, the information will be imported into the ERP system and the system will automatically generate accounting documents based on the imported information, as shown in Figure 2. The use of network reimbursement system to computerized accounting information processing advance to the original voucher processing stage reduces the tedious accounting staff basic work. While improving the standardization of information, it reduces human error in accounting and improves the financial Accounting quality. 


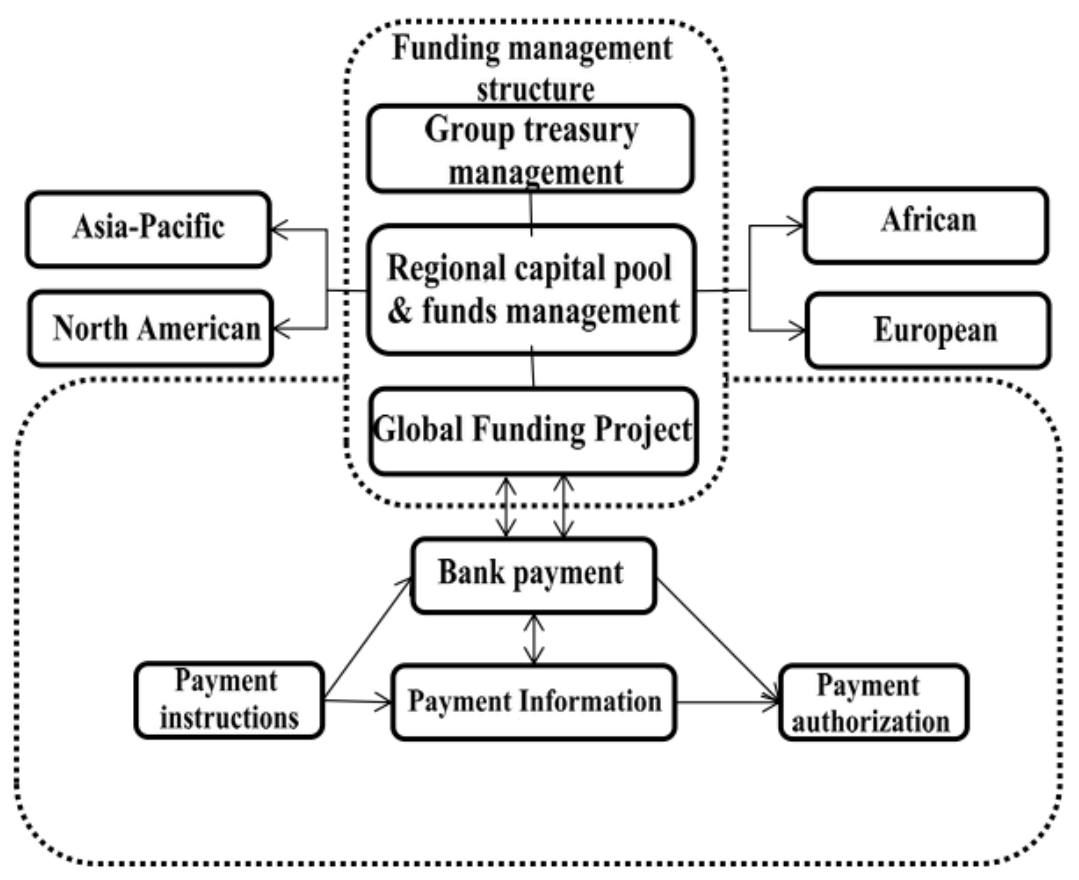

Fig.2 Capital management system processing flow chart

(3) Financial accounting system. Group A employs enterprise resource planning (ERP) software from Oracle, a world-renowned software company. The software has been in operation for more than ten years and has a more mature management system. However, as a group A with subsidiaries all over the world, the software is still not enough to meet its needs. Therefore, Group A's "Financial Cloud" has also been functionally optimized and reformed in this system. As some countries' accounting standards, policies and other aspects compared with the international and China are different. In order to meet the relevant standards of these countries and facilitate the statutory requirements of local tax departments, third-party agencies and auditing departments, Finance Cloud optimizes the company's A / C set of accounts so that an accounting business can be accounted for locally and group two sets of accounting subjects, and it can generate output of two sets of local and group accounting statements. In addition, due to the ERP system and the local accounting software docking, all the accounting information uploaded can use the local accounting code to obtain the corresponding information generated after the statutory requirements of the local accounting entries, and it can generate accounting reports.

(4) Electronic file system. The management and accounting of funds in the "financial cloud" processing system can be managed uniformly. The management of accounting records can also be managed through the "financial cloud" platform. Electronic file system is based on ERP system. Through the network reimbursement system, image management system will be collected by the image data, generated electronic voucher unified classification, coding, and the original voucher to match each other to form a complete electronic file, reducing the Due to the different forms of external documents, irregular format. Internal transmission is easy to lose and other issues, extending the shelf life of the file and improving the file security.

(5) Fund management system. In order to facilitate the unified management of funds and make them more standardized and efficient, Group A's financial cloud platform has established a unified treasury management system with group treasury management, regional fund pool and state treasury and global fund disbursement factory as the core, among which the pool of funds tends to include the four major pools of funds in Asia Pacific, North America, Africa and Europe. At the same time, it is safer and more efficient for the payment system to issue payment instructions from the issuance of the payment instruction to the authorization, as well as the instantaneous exchange of information between the bank and the financial cloud platform. 


\section{CONCLUSION}

With the deepening of global economic integration, multinational corporations have continuously increased their investment in China. As a result, the "shared service model" has been introduced into China. More and more enterprise groups have set up financial sharing service platforms and are actively operating. With the rapid development of modern information technology, under the background of "Dazhigyun", the accounting profession should be fully prepared to deal with the challenges it poses. It should take the initiative to participate in the financial sharing and informatization construction projects, which makes full use of accounting information platform and other platforms to seek to capitalize on big data and cloud computing to enhance their accounting capabilities. This will further improve efficiency, improve service, promote transformation and enhance the core value of the enterprise. This paper studied and analyzed the construction of financial sharing service platform based on ERP supply chain management in cloud computing environment. The ERP system based on cloud computing was more convenient and flexible than the traditional ERP system. At the same time, it provided enterprises with a modern enterprise management mode with less input costs but satisfying all kinds of requirements at any time. Through case analysis, this paper has deeply explored the main value of the implementation of China's financial sharing platform, which is mainly reflected in the significant changes in the cost and efficiency of enterprises, the innovation of financial management concepts and models, and the innovation of business management models. The research in this paper can provide valuable experience for enterprises to build a financial sharing platform in the context of "Dazhigyun".

\section{References}

[1] Pederson P, Dudenh oeffer D, Hartley S, et al. Critical infrastructure interdependency modeling: a survey of US and international research[J]. Idaho National Laboratory, 2006, 25: 27.

[2] Swan L G, Ugursal V I. Modeling of end-use energy consumption in the residential sector: A review of modeling techniques[J]. Renewable and sustainable energy reviews, 2009, 13(8): 1819-1835.

[3] Zhang T, Gensler S, Garcia R. A Study of the Diffusion of Alternative Fuel Vehicles: An Agent-Based Modeling Approach[J]. Journal of Product Innovation Management, 2011, 28(2): 152-168.

[4] Hamit-Haggar M. Greenhouse gas emissions, energy consumption and economic growth: A panel cointegration analysis from Canadian industrial sector perspective[J]. Energy Economics, 2012, 34(1): 358-364.

[5] Chang Y, Ries R J, Wang Y. The embodied energy and environmental emissions of construction projects in China: an economic input-output LCA model[J]. Energy Policy, 2010, 38(11): 6597-6603.

[6] Frey H C, Rouphail N M, Zhai H, et al. Comparing real-world fuel consumption for diesel-and hydrogen-fueled transit buses and implication for emissions[J]. Transportation Research Part D: Transport and Environment, 2007, 12(4): 281-291.

[7] Chang Y, Ries R J, Wang Y. The embodied energy and environmental emissions of construction projects in China: an economic input-output LCA model[J]. Energy Policy, 2010, 38(11): 6597-6603.

[8] Kennewell, S., Baker L..Benefits and risks of shared services in healthcare[J].Journal of Health, Organisation and Management, 2016 (3):441 456.

[9] LAWERENCE J, TRAUTMAN.Is disruptive blockchain technology the future of financial services? [J]. Quarterly Report,2017(1):232-242. 
[10]KURT F, DAVID P.Centers, block chain and its coming impact on financial services[J].The Journal of Corporate Accounting \& Finance,2016(4):53-57.

[11]SUNJ J.Block chain-based sharing services: What blockchain technology can contribute to smart cities [J].Financial Innovation,2016(2):1-9.

[12]Huang Qin. Research on the Impact of Financial Sharing Service on Corporate Financial Performance — Taking ZTE as an Example[A]. Institute of Management Science and Industrial Engineering. Proceedings of 2019 2nd International Conference on Global Economy, Finance and Humanities Research (GEFHR 2019) [C]. Institute of Management Science and Industrial Engineering: 2019:5.

[13]Bojin Yao. Discussion on the Management Mode of Enterprise Financial Sharing Services[A]. Institute of Management Science and Industrial Engineering. Proceedings of 2018 5th International Conference on Education, Management and Computing Technology (ICEMCT 2018) [C]. Institute of Management Science and Industrial Engineering: 2018:5. 